\title{
Worry from contracting COVID-19 infection and its stigma among Egyptian health care providers
}

Doaa Mohamed Osman ${ }^{1 *}$, Fatma R. Khalaf', Gellan K. Ahmed ${ }^{3,4}$, Ahmed Y. Abdelbadee ${ }^{5}$, Ahmed M. Abbas ${ }^{5}$ and Heba M. Mohammed ${ }^{1}$

\begin{abstract}
Backgrounds: Healthcare providers (HCPs) in COVID-19 epidemic face stressful workload of disease management, shortage of protective equipment and high risk of infection and mortality. These stressors affect greatly their mental health. The aim is to identify working conditions among Egyptian HCPs during COVID-19 epidemic as well as stigma and worry perceptions from contracting COVID-19 infection and their predictors.

Methods: A cross-sectional study was conducted among 565 HCPs. Data was collected through Google online selfadministered questionnaire comprised seven parts: demographics characteristics, knowledge and attitude of COVID19, working condition, worry of contracting COVID-19 at work, discrimination intention at work for COVID-19 patients, stigma assessment using impact stigma, and internalized shame scales.

Results: The vast majority of HCPs (94.7\%) were worried from contracting COVID-19 at work. Risk factors for perceiving severe worry from contracting COVID-19 were expecting infection as a severe illness, believing that infection will not be successfully controlled, improbability to continue working during the pandemic even if in a well/fit health, high discrimination intention and impact stigma scales. Significantly high impact stigma scores were detected among those aged $<30$ years, females, workers primarily in sites susceptible for contracting COVID-19 infection, those had severe worry from contracting infection at work, and high internalized shame scale. The risk factors for perceiving higher internalized shame scores were not having a previous experience in working during a pandemic, high discrimination intention towards COVID-19 patients and high impact stigma scale.

Conclusions: Considerable levels of worry and stigma were detected among Egyptian HCPs during COVID-19 outbreak. The psychological aspect of health care providers should not be overlooked during epidemic; appropriate institutional mental health support should be provided especially for young HCPs, those without previous work experience in epidemic and those who work in high-risk units. Raising the community awareness about contribution of HCPs in fighting the epidemic might decrease stigmatization action toward HCPs.
\end{abstract}

Keywords: Health care providers, Egypt, Worry, Stigma, COVID-19

\footnotetext{
* Correspondence: doaamouhammed@aun.edu.eg

'Department of Public Health and Community Medicine, Faculty of

Medicine, Assiut University, Assiut, Egypt

Full list of author information is available at the end of the article
}

\section{Springer Open}

(c) The Author(s). 2021 Open Access This article is licensed under a Creative Commons Attribution 4.0 International License, which permits use, sharing, adaptation, distribution and reproduction in any medium or format, as long as you give appropriate credit to the original author(s) and the source, provide a link to the Creative Commons licence, and indicate if changes were made. The images or other third party material in this article are included in the article's Creative Commons licence, unless indicated otherwise in a credit line to the material. If material is not included in the article's Creative Commons licence and your intended use is not permitted by statutory regulation or exceeds the permitted use, you will need to obtain permission directly from the copyright holder. To view a copy of this licence, visit http://creativecommons.org/licenses/by/4.0/. 


\section{Introduction}

Since the announcement of the Chinese authorities in Wuhan City on the novel coronavirus (COVID-19) in December 2019, the epidemic has expanded from Wuhan throughout China and disseminated to every country across the world [1]. As of 30 November, 2021 there are 261.5 million confirmed cases of COVID-19, including 5.2 million deaths worldwide [2].

COVID-19 infection occurs mainly by contact or droplet transmission. In addition, airborne infection may develop in case of respiratory aerosols production with patient respiratory activity or medical procedures [3].

Similar to the preceding communicable disease epidemics, healthcare workers in COVID-19 epidemic are at the front line in terms of risk of infection and mortality [4]. Health care systems worldwide have become overburdened with possibly infectious patients seeking testing and health care. Personal protective equipment (PPEs) are important during the current COVID-19 pandemic [3]. A critical lack of protective equipment is predicted to occur or has already occurred in high demand areas [5].

The rapid spread of COVID-19 infection across the world caused a degree of fear and worry in the general population and specifically among certain groups as elderly, people with underlying health conditions and health care providers (HCPs) [6]. During epidemics, the mental health of HCPs is seriously challenged. In the early phase, psychological distress as fear and anxiety appear then gradually decline. Later on, depression, and posttraumatic stress symptoms appear and persist for a long time, leading to considerable impact. HCPs isolation, working in high-risk sites, and dealing with infected patients are the main reasons of trauma. Moreover, some HCPs may experience avoidance by their family or community $[7,8]$.

In Egypt, the first case of COVID-19 was confirmed on 14 February 2020 [9], then there was growing rise in the number of confirmed cases and deaths. Concurrently, there was a parallel rise in the number of infected HCPs including physicians and nurses. This study aimed to identify the working conditions among Egyptian HCPs during COVID-19 epidemic as well as the perception of stigma and worry from contracting this infection and their predictors.

\section{Methods}

\subsection{Study design and population:}

An online survey was conducted on 565 Egyptian HCPs. HCPs were physicians, nurses, and health officers (both medical and nursing specialty).

\subsection{Sample size and technique:}

The sample size was estimated using the EPI info statistical package, Version 7. The used parameters were a proportion of 0.5 , a confidence level of $95 \%$ and a margin of error of $5 \%$. Sample size was 384 HCPs and $10 \%$ as non-response rate was added. Non-probability convenience sampling technique was applied. Data was collected using Google online self-administered questionnaire disseminated in Arabic language. The questionnaire link was distributed using social networks through either personal communication or physician/nurses gathering groups. Data was collected from 24th April till 7th May 2020.

\subsection{The used tool}

The self-administered questionnaire consisted of seven parts:

1. Demographics characteristics: age, gender, marital status, education, occupation, years of experience, and residence either urban/rural and governorate.

2. Knowledge about COVID-19 included 12 questions, each question had three answer options as true, false and "I do not know." One point was assigned for each correct answer while zero point was assigned for the incorrect or unknown answer [10].

3. Attitude toward control of COVID-19 was inquired by two questions. Whether he/she agree that COVID-19 will finally be successfully controlled, and if he/she has the confidence that Egypt can control the epidemic? $[10,11]$

4. Working conditions during epidemic were assessed using red caps questionnaire for health care providers about COVID-19 [12].

5. One statement assessed worry of contracting COVID-19 at work since announcement of the first COVID-19 case in Egypt. The response categories were not at all worried, somewhat worried, and very worried [13].

6. Discrimination intention at work for COVID-19 patients was measured. Discrimination intention was assessed using four items each item scored from 1 (strongly disagree) to 5 (strongly agree) point. The total score ranged from 4 points to 20 points. Higher scores meant less discrimination intent toward COVID-19 patients [14]. The reliability of the discrimination intention scale assessed by using Cronbach's alpha was 0.959 .

7. Two scales were used to assess stigma perception by HCPs due to their dealing with COVID-19 patients. The questions were derived from scales used to assess stigma from dealing with patients living with HIV as a serious disease [15], each item was scored from 1 (strongly disagree) to 5 (strongly agree) point and higher scores indicated more perception of stigma. The first scale measured the perceived impact of working with COVID-19 or its 
related field. The second was the Internalized Shame Scale measured how the providers felt about their work with COVID-19 patients. The reliability of the impact and internalized shame scales assessed using Cronbach's alpha were 0.802, 0.685 respectively.

\subsection{Statistical analysis}

Data was analyzed using the Statistical Package for Social Science (SPSS), version 16.0 for Windows. Mean and standard deviation were used to express quantitative data while qualitative data was presented using frequencies and percentages. Unadjusted and adjusted logistic regression models were applied to identify predictors of being very worried from contracting COVID-19 at work as a dependent variable (very worried $=1$ and somewhat worried/not worried at all $=0$ ). Unadjusted and adjusted linear regression models were used to identify predictors of stigma both impact and internalized shame scales. The explanatory variables entered in the adjusted regression models were age and gender and the significant variables resulted from the unadjusted models. Significance of statistical tests was at $P$ value $<0.05$.

\section{Results}

Table 1 shows the sociodemographic characteristics of the studied HCPs $(n=565)$ were as follows: participants aged 25 to 40 years old were $69.4 \%$. Females represented $70.6 \%$ of the participants, urban residents formed more than three quarters (77.3\%) and the majority (95.4\%) were residing in Upper Egypt. More than half of the participants were physicians (53.6\%), while nurses formed $22.7 \%$. Concerning work experience duration, the highest percentage of providers had more than 6 years' experience $(45.8 \%)$. Married subjects were $51.5 \%$. Among ever-married subjects $(n=302), 86.1 \%$ had children.

Table 2 shows the working conditions and personal perceptions of COVID-19. Forty percent of the studied HCPs were primarily working in sites with higher probability for contracting COVID-19 infection. Nearly onefifth (19\%) had an experience in working during previous pandemics. Those reported exposure to even one diagnosed or suspicious COVID-19 patient were 31.7\%. About 35\% received training on COVID-19, 71.5\% received updated guidelines on occupational safety and $22.3 \%$ of the participants reported that their institutions provided psychological/mental health support. The majority of studied subjects applied changes in their personal protection after announcement of COVID-19 cases in Egypt. Nearly 70\% intended to continue work during COVID-19 pandemic if they were fit/in well health. The majority perceived COVID-19 as severe disease and making their loved ones sick and becoming sick were the main personal worries of the participants. The
Table 1 Socio-demographic characteristics of the studied health care provider, Egypt (2020)

\begin{tabular}{|c|c|c|}
\hline Variable & $n=565$ & $\%$ \\
\hline \multicolumn{3}{|l|}{ Age } \\
\hline Less than 25 & 108 & 19.1 \\
\hline $25-30$ & 204 & 36.1 \\
\hline $30-40$ & 188 & 33.3 \\
\hline$>40$ & 65 & 11.5 \\
\hline \multicolumn{3}{|l|}{ Gender } \\
\hline Male & 166 & 29.4 \\
\hline Female & 399 & 70.6 \\
\hline \multicolumn{3}{|l|}{ Residence } \\
\hline Urban & 437 & 77.3 \\
\hline Rural & 128 & 22.7 \\
\hline \multicolumn{3}{|l|}{ Governorate } \\
\hline North upper Egypt & 181 & 32.0 \\
\hline Middle upper Egypt & 209 & 37.0 \\
\hline South upper Egypt & 149 & 26.4 \\
\hline Others & 26 & 4.6 \\
\hline \multicolumn{3}{|l|}{ Occupation } \\
\hline Health officer & 109 & 19.3 \\
\hline Nursing officer & 25 & 4.4 \\
\hline Physician & 303 & 53.6 \\
\hline Nurse & 128 & 22.7 \\
\hline \multicolumn{3}{|l|}{ Years of experiences } \\
\hline$<2$ years & 173 & 30.6 \\
\hline $2-<4$ years & 72 & 12.7 \\
\hline $4-6$ years & 61 & 10.8 \\
\hline$>6$ years & 259 & 45.8 \\
\hline \multicolumn{3}{|l|}{ Marital status } \\
\hline Single & 263 & 46.5 \\
\hline Married & 291 & 51.5 \\
\hline Widow/divorced & 11 & 2.0 \\
\hline \multicolumn{3}{|c|}{ Having children $(n=302)$} \\
\hline Yes & 260 & 86.1 \\
\hline No & 42 & 13.9 \\
\hline
\end{tabular}

total COVID-19 knowledge score ranged from 6 to 12 with a mean of $10.92 \pm 0.92$. Those who agreed that COVID-19 pandemic will be successfully controlled were $73.8 \%$ and $47.6 \%$ were confident that Egypt can control the epidemic. The majority of Egyptian HCPs were worried from contracting COVID-19 at work; either very worried (35.6\%) or somewhat worried (59.1\%).

Nearly half of participants had no discrimination intents towards management of COVID-19 cases either working with COVID-19 patients, providing care, performing physical examination and interacting with 
Table 2 Working conditions and personal perceptions of COVID-19 among the study health care providers, Egypt (2020)

Variables
Whether primarily work in ED, ICU, or
infectious diseases dep.
Yes
No
Having direct experiences in working
during a previous pandemic
Yes
No
Exposure to at least one diagnosed/
suspicious COVID-19-infected person
Yes
No

Receiving any training about COVID-19

Yes

No

Receiving appropriate guidelines on updated procedures for personal safety to be followed at work

Yes

No

Availability of institutional psychological/ mental health support

Yes

No

Being redirected to COVID-19-related activities

Yes

No

Applied changes in personal protection after COVID-19 hit Egypt \#

Started routinely wearing masks

Started using hand sanitizer/more frequent

hand washing

Started wearing scrubs/disposable clothes

Started social distancing

Deciding not to wear a mask or other PPE \#

No never
Yes, because none of my colleagues was wearing it

Yes, because my employer did not recommend it

Yes, because it is uncomfortable/inconvenient

Yes, because I do not believe I need to wear it

Yes, because it is not available

Probability of work continuation during COVID-19 pandemic if they are fit/well

Extremely unlikely

Unlikely

Neutral

$n=565 \%$

Table 2 Working conditions and personal perceptions of COVID-19 among the study health care providers, Egypt (2020) (Continued)

\begin{tabular}{lll}
\hline Variables & $\boldsymbol{n}=\mathbf{5 6 5}$ & $\mathbf{\%}$ \\
\hline Likely & 195 & 34.5 \\
Extremely likely & 204 & 36.1 \\
Personal perception of severity of COVID-19 & & \\
Not severe & 25 & 4.4 \\
Neutral & 76 & 13.5 \\
Simple & 5 & 0.9 \\
Severe & 459 & 81.2
\end{tabular}

Personal worries about working during COVID-19 pandemic \#

\begin{tabular}{|c|c|c|}
\hline Becoming sick & 311 & 55.0 \\
\hline Making my loved ones sick & 538 & 95.2 \\
\hline $\begin{array}{l}\text { Not having the appropriate skills to care } \\
\text { for COVID-19 patients }\end{array}$ & 200 & 35.4 \\
\hline $\begin{array}{l}\text { Not having adequate supplies to care } \\
\text { for COVID-19 patients }\end{array}$ & 260 & 46.0 \\
\hline Others $\$$ & 18 & 3.2 \\
\hline \multicolumn{3}{|l|}{ Worry from contracting COVID 19 at work } \\
\hline Very worry & 201 & 35.6 \\
\hline Somewhat worry & 334 & 59.1 \\
\hline Not worried at all & 30 & 5.3 \\
\hline
\end{tabular}

COVID-19 patients similar to non-COVID-19 cases. Due to their work with COVID-19 patients or its related field, nearly $40 \%$ of participants suffered discrimination or stigma outside work or noticed that people were moving away from them at some social functions and $54.4 \%$ reported unhappiness of their families. On the other hand, lower percentages reported reduction of contact by friends (28.2\%) and suffering discrimination or stigma from their colleagues (16.6\%) due to the same cause. About one-fifth of the studied health care providers felt embarrassed to tell people about their work nature and wished if they could change their occupation or would never deal with COVID-19 patients. The mean of the discrimination intent scale was $12.04 \pm 4.42$, while impact scale was $13.90 \pm 4.18$ and internalized shame scale was $4.62 \pm 1.97$ (Table 3 ).

Table 4 displayed the risk factors of worrying from contracting COVID-19 infection at work among studied health care providers. In the adjusted model, the significant predictors were perceiving COVID-19 as severe disease $(\mathrm{OR}=1.99 ; P=0.011)$, believing that COVID-19 infection will not be successfully controlled $(\mathrm{OR}=1.70$; $P=0.033)$, improbability to continue working during the 
Table 3 Discrimination intent and stigma (impact and internalized shame scales) among the studied health care providers, Egypt (2020)

\begin{tabular}{|c|c|c|c|c|c|}
\hline Scale & $\begin{array}{l}\text { Strongly } \\
\text { disagree }\end{array}$ & Disagree & $\begin{array}{l}\text { Neither agree } \\
\text { nor disagree }\end{array}$ & Agree & $\begin{array}{l}\text { Strongly } \\
\text { agree }\end{array}$ \\
\hline \multicolumn{6}{|l|}{ Discrimination intent scale } \\
\hline Willing to work with COVID-19 patients & $88(15.6)$ & $120(21.2)$ & $85(15.0)$ & $260(46.0)$ & $12(2.1)$ \\
\hline Willing to provide same care as other patients & $75(13.3)$ & $114(20.2)$ & $83(14.7)$ & $279(49.4)$ & $14(2.5)$ \\
\hline Willing to do physical exam of COVID-19 patient as other patients & $85(15.0)$ & $126(22.3)$ & $73(12.9)$ & $271(48.0)$ & $10(1.8)$ \\
\hline Willing to interact same as other patients & $91(16.1)$ & $113(20.0)$ & $78(13.8)$ & $269(47.6)$ & $14(2.5)$ \\
\hline Mean \pm SD (range) & \multicolumn{3}{|c|}{$12.04 \pm 4.42(4.00-20.00)$} & & \\
\hline \multicolumn{6}{|l|}{$\begin{array}{l}\text { The perceived stigma using impact scale: Since announcement of } \\
\text { COVID-19 cases in Egypt }\end{array}$} \\
\hline $\begin{array}{l}\text { Suffering discrimination or stigma outside work due to working in } \\
\text { COVID-19-related field. }\end{array}$ & $69(12.2)$ & $186(32.9)$ & $80(14.2)$ & $207(36.6)$ & $23(4.1)$ \\
\hline $\begin{array}{l}\text { Friends decreased their contact with you since you started working with } \\
\text { COVID-19 patients or its related field. }\end{array}$ & 105 (18.6) & $214(37.9)$ & $87(15.4)$ & $144(25.5)$ & $15(2.7)$ \\
\hline $\begin{array}{l}\text { People move away from you at social functions when hearing that you } \\
\text { work with COVID-19 patients or its related field. }\end{array}$ & $54(9.6)$ & $164(29.0)$ & $94(16.6)$ & $228(40.4)$ & $25(4.4)$ \\
\hline $\begin{array}{l}\text { Unhappiness of family due to working with COVID-19 patients or its } \\
\text { related field. }\end{array}$ & $54(9.6)$ & $124(21.9)$ & $80(14.2)$ & $262(46.4)$ & $45(8.0)$ \\
\hline $\begin{array}{l}\text { Suffering discrimination or stigma from other staff at the hospital due } \\
\text { to the work with COVID-19 patients or its related field. }\end{array}$ & $134(23.7)$ & $256(45.3)$ & $81(14.3)$ & $86(15.2)$ & $8(1.4)$ \\
\hline Mean \pm SD (range) & \multicolumn{3}{|c|}{$13.90 \pm 4.18(5.00-20.00)$} & & \\
\hline \multicolumn{6}{|l|}{ Internalized shame scale } \\
\hline $\begin{array}{l}\text { If you worked with COVID-19 patients, you would feel embarrassed to } \\
\text { tell other people about it. }\end{array}$ & $161(28.5)$ & $226(40.0)$ & $61(10.8)$ & $104(18.4)$ & $13(2.3)$ \\
\hline $\begin{array}{l}\text { If you worked with COVID-19 patients, you would wish that you could } \\
\text { change your job so that you would never have to deal with } \\
\text { COVID-19 patients. }\end{array}$ & $136(24.1)$ & $226(40.0)$ & $81(14.3)$ & $103(18.2)$ & $19(3.4)$ \\
\hline Mean \pm SD (range) & \multicolumn{2}{|c|}{$4.62 \pm 1.97(2.00-10.00)$} & & & \\
\hline
\end{tabular}

COVID-19 coronavirus disease-2019, SD standard deviation

COVID-19 pandemic even in a well/fit health $(\mathrm{OR}=1.88$; $P=0.005)$. In addition, high discrimination intention towards COVID-19 patients (as low scores indicate high discrimination intention) $(\mathrm{OR}=0.88 ; P<0.001)$ and perceiving stigma resulted from actions of surrounded subjects using impact scale $(\mathrm{OR}=1.08 ; P=0.003)$ were risk factors.

Table 5 displayed the adjusted and unadjusted linear regression models for identifying risk factors for perceiving stigma resulted from actions of surrounded subjects (impact scale) among HCPs. In the adjusted model, the significant predictors were age less than 30 years, being female, primarily working in sites lending them susceptible for contracting COVID-19 infection, severe worry from contracting COVID-19 infection at work, and high perception of internalized shame from dealing with COVID-19 patients or working in its related field $(P<0.05)$.

The adjusted multivariate linear regression model showed that not having a previous experience in working during pandemic ( $B=0.42 ; P=0.036$ ), high discrimination intention towards COVID-19 patients (as low scores indicate high discrimination intention) $(B=$ 0.14; $P<0.001)$ and high perception of stigma resulted from actions of surrounded subjects $(B=1.08 ; P<0.001)$ were significant predictors for perceiving internalized shame among the studied Egyptian HCPs (Table 6).

\section{Discussion}

COVID-19 is an emerging highly infectious disease transmitted swiftly from one country to the other. The World Health Organization main concern when declaring the disease as a public emergency was "if the virus spreads to countries with stretched health care system, will they stand it or collapse" [16]. In our study, we present the results of a survey investigating the knowledge, attitude, worry from contracting COVID-19 infection, and its stigma among Egyptian HCPs and analyzing potential risk factors for their perceived worry and stigmatization.

\subsection{Knowledge of the disease and attitude towards it} Dealing with a public health emergency as COVID-19 requires that HCPs be aware of the disease, its mode of transmission, diagnosis, prevention, and management protocols. In our study, the average correct answers were very high indicating that Egyptian HCPSs were working 
Table 4 Predictors of severe worry of contracting COVID-19 infection at work among the studied health care providers, Egypt (2020)

\begin{tabular}{|c|c|c|c|c|c|c|}
\hline \multirow[t]{2}{*}{ Variable } & \multicolumn{3}{|c|}{ Unadjusted logistic regression } & \multicolumn{3}{|c|}{ Adjusted logistic regression } \\
\hline & Odds ratio & $95 \% \mathrm{Cl}$ & $P$ value & Odds ratio & $95 \% \mathrm{Cl}$ & $P$ value \\
\hline Age (<30 years) & 1.55 & $1.09-2.21$ & 0.01 & 1.30 & $0.87-1.96$ & 0.200 \\
\hline Gender (female) & 1.16 & $0.79-1.70$ & 0.43 & 0.88 & $0.57-1.37$ & 0.572 \\
\hline Marital status (married) & 1.22 & $0.86-1.726$ & 0.25 & & & \\
\hline Occupation (doctors) & 1.19 & $0.80-1.76$ & 0.38 & & & \\
\hline Years of experience $(<4$ years $)$ & 1.36 & $0.96-1.92$ & 0.08 & & & \\
\hline Primarily work in ED, ICU, or infectious diseases dep. (yes) & 1.29 & $0.90-1.83$ & 0.15 & & & \\
\hline Experience in working during a previous pandemic (no) & 1.47 & $0.93-2.32$ & 0.09 & & & \\
\hline $\begin{array}{l}\text { Exposure to at least one person who has been diagnosed or } \\
\text { had symptoms suggestive of COVID-19 infection (yes) }\end{array}$ & 0.81 & $0.56-1.18$ & 0.28 & & & \\
\hline Receiving any training about COVID-19 (no) & 1.21 & $0.84-1.75$ & 0.29 & & & \\
\hline $\begin{array}{l}\text { Receive appropriate guidelines on updated procedures } \\
\text { related to personal safety to follow at work (no) }\end{array}$ & 1.85 & $1.27-2.69$ & 0.001 & 1.27 & $0.81-1.98$ & 0.293 \\
\hline Employer provision of adequate PPE (no) & 1.93 & $1.36-2.74$ & $<0.001$ & 1.23 & $0.81-1.87$ & 0.325 \\
\hline $\begin{array}{l}\text { Availability of institutional psychological/mental health } \\
\text { support (no) }\end{array}$ & 1.50 & $0.97-2.31$ & 0.06 & & & \\
\hline Being redirected to activities related to COVID-19 (yes) & 0.95 & $0.65-01.39$ & 0.80 & & & \\
\hline Personal perception of COVID-19 (severe disease) (severe) & 1.78 & $1.11-2.87$ & 0.017 & 1.99 & $1.17-3.39$ & 0.011 \\
\hline Thinking that COVID-19 will finally be successfully controlled (no) & 2.56 & $1.74-3.76$ & $<0.001$ & 1.70 & $1.04-2.76$ & 0.033 \\
\hline Confidence that Egypt can control the epidemic (no) & 2.25 & $1.58-3.22$ & $<0.001$ & 1.43 & $0.91-2.25$ & 0.119 \\
\hline $\begin{array}{l}\text { Underestimating dangerous effect of COVID-19 on general health } \\
\text { in its early days (no) }\end{array}$ & 1.48 & $1.04-2.10$ & 0.02 & 1.30 & $0.88-1.93$ & 0.188 \\
\hline $\begin{array}{l}\text { Probability of work continuation during COVID-19 pandemic if } \\
\text { she/he is fit/well? (unlikely) }\end{array}$ & 2.96 & $2.03-4.31$ & $<0.001$ & 1.88 & $1.21-2.91$ & 0.005 \\
\hline Knowledge score & 0.97 & $0.81-1.77$ & 0.80 & & & \\
\hline Discrimination intent score & 0.85 & $0.81-0.88$ & $<0.001$ & 0.88 & $0.84-0.93$ & $<0.001$ \\
\hline Impact stigma score & 1.10 & $1.05-1.15$ & $<0.001$ & 1.08 & $1.03-1.14$ & 0.003 \\
\hline Internalized shame scale & 1.29 & $1.17-1.413$ & $<0.001$ & 1.03 & $0.92-1.16$ & 0.560 \\
\hline
\end{tabular}

$E D$ emergency department, ICU intensive care unit, COVID-19 coronavirus disease-2019, PPE personal protective equipment

Bold values: statistically significant at $P$ value $<0.05$

with reliable knowledge about the disease in spite of the continuously evolving situation. Our findings suggest that despite false information circulated on social media, Egyptian HCPs were keen to seek the scientific evidence in comparison to other HCPs in the region [17]. Similarly, a systematic review of 20 studies involved 12,072 HCPs assessed the knowledge level about novel Coronavirus-19 during the initial pandemicreported that three fourths of HCPs had good understanding of COVID-19. The study emphasized the role of good knowledge level about COVID-19 disease in improvement of the diagnosis, delaying disease spread, and applying good infection control practices [18].

While nearly three quarters were confident that the pandemic will be eventually controlled globally, less than half were pessimistic that Egypt will have better chances for controlling it. This belief stems from the fact that they are aware of the already overburdened health care system in Egypt as a developing country, and to the challenges faced in recruiting, retaining, and protecting sufficient well-trained, supported, and motivated health workers and overcoming any possible shortage of equipment, drugs, and supplies.

\subsection{Working conditions and perceptions about the disease}

In our study, $40 \%$ only of the respondents worked in emergency departments, intensive care units, or infectious diseases departments and the majority had no prior experience with facing pandemics. Nearly one third report that they were exposed to a suspected or confirmed COVID-19 patient. While the majority state that they did not receive specific training on COVID-19 at the time the study was conducted, they still report that they received appropriate guidance on updated procedures for personal safety to be implemented at work. On the contrary, more than half (57\%) of Pakistani health care providers reported receiving COVID-19-related training, 
Table 5 Predictors of stigma (impact scale) among the studied health care providers, Egypt (2020)

\begin{tabular}{|c|c|c|c|c|c|c|}
\hline \multirow[t]{2}{*}{ Variable } & \multicolumn{3}{|c|}{ Unadjusted linear regression } & \multicolumn{3}{|c|}{$\begin{array}{l}\text { Adjusted linear regression } \\
\left(R^{2}=0.19\right)\end{array}$} \\
\hline & B & $95 \% \mathrm{Cl}$ & $P$ value & $B$ & $95 \% \mathrm{Cl}$ & $P$ value \\
\hline Age (< 30 years) & 1.31 & $0.62-1.99$ & $<0.001$ & 1.05 & $0.41-1.69$ & 0.001 \\
\hline Gender (female) & -0.59 & $-1.34-0.16$ & 0.12 & -0.71 & -1.40 to -0.01 & 0.046 \\
\hline Occupation (doctors) & -0.28 & $-1.06-0.49$ & 0.46 & & & \\
\hline Years of experience $(<4$ years $)$ & 1.31 & $0.61--1.99$ & $<0.001$ & & & \\
\hline Primarily work in ED, ICU, or infectious diseases dep. (yes) & 0.81 & $0.11-1.52$ & 0.02 & 1.05 & $0.40-1.70$ & 0.002 \\
\hline Experience in working during a previous pandemic (no) & -0.45 & $-1.33-0.42$ & 0.30 & & & \\
\hline $\begin{array}{l}\text { Availability of institutional psychological/mental health } \\
\text { support (no) }\end{array}$ & 0.55 & $-0.27-1.38$ & 0.189 & & & \\
\hline Personal perception of COVID-19 (severe disease) & 0.70 & $-0.18-1.58$ & 0.12 & & & \\
\hline Worry from contracting COVID-19 at work (severe worry) & 1.66 & $0.95-2.37$ & $<0.001$ & 0.79 & $0.11-1.47$ & 0.024 \\
\hline Knowledge score & -0.48 & -0.86 to -0.11 & 0.01 & -0.29 & $-0.63-0.06$ & 0.100 \\
\hline Discrimination intent score & -0.05 & $-0.13-0.026$ & 0.187 & & & \\
\hline Internalized shame scale & 0.78 & $0.61-0.94$ & $<0.001$ & 0.74 & $0.57-0.91$ & $<0.001$ \\
\hline
\end{tabular}

ED emergency department, ICU intensive care unit, COVID-19 coronavirus disease-2019

Bold values: statistically significant at $P$ value $<0.05$

such as PPE use (donning, doffing), social distancing, isolation, quarantine, and lock-down [19].

Our study highlighted the lack of appropriate institutional mental health support which is a concerning finding in our study. While only one third reported that they were directed to COVID-19-related activities, the majority exhibited changes to their personal protection as routinely wearing face masks, frequent hand hygiene, and practicing social distancing. Another concerning finding our study revealed was that less than one third started wearing scrubs or disposable clothes which was attributed to the shortage in PPEs available. In accordance, the WHO recommends frequent hand hygiene, wearing medical mask, and maintaining social distance as the most effective preventive measures in the community [20]. These positive habit changes were reported in Ethiopia and United Arab Emirates [21, 22].

World Health Organization and Occupational Safety and Health Administration (OSHA) ensured the necessity of provision of personal protective equipment, appropriate training, safe working conditions for the safety of both health worker and patients [23, 24]. However, shortage of personal protective equipment had been experienced by many affected counties regardless of their

Table 6 Predictors of perceiving internalized shame among the studied health care providers, Egypt (2020)

\begin{tabular}{|c|c|c|c|c|c|c|}
\hline \multirow[t]{2}{*}{ Variable } & \multicolumn{3}{|c|}{ Unadjusted } & \multicolumn{3}{|c|}{ Adjusted $\left(R^{2}=0.28\right)$} \\
\hline & $\bar{B}$ & $95 \% \mathrm{Cl}$ & $P$ value & $\bar{B}$ & $95 \% \mathrm{Cl}$ & $P$ value \\
\hline Age (<30 years) & 0.26 & $-0.06-0.59$ & 0.11 & -0.21 & $-0.51-0.10$ & 0.188 \\
\hline Gender (female) & -0.03 & $-0.38-0.32$ & 0.86 & -0.14 & $-0.45-0.17$ & 0.376 \\
\hline Occupation (doctors) & 0.70 & $0.33-1.06$ & $<0.001$ & 0.33 & $-0.02-0.68$ & 0.068 \\
\hline Experience years $(<4$ years) & 0.27 & $-0.05-0.60$ & 0.10 & & & \\
\hline Primarily work in ED, ICU, or infectious diseases dep. (yes) & -0.49 & -0.82 to -0.16 & 0.004 & -0.15 & $-0.48-0.17$ & 0.355 \\
\hline Experience in working during a previous pandemic (no) & 0.73 & $0.32-1.14$ & $<0.001$ & 0.42 & $0.03-0.81$ & 0.036 \\
\hline $\begin{array}{l}\text { Availability of institutional psychological/mental health } \\
\text { support (no) }\end{array}$ & 0.23 & $-0.15-0.62$ & 0.23 & & & \\
\hline Personal expectation about COVID-19 (severe disease) & 0.25 & $-0.16-0.66$ & 0.23 & & & \\
\hline Worry from contracting COVID-19 at work (severe worry) & 0.97 & $0.64-1.30$ & $<0.001$ & 0.28 & $-0.04-0.61$ & 0.084 \\
\hline Knowledge score & -.149 & $-0.32-0.02$ & 0.09 & & & \\
\hline Discrimination intent score & -0.16 & -0.19 to -0.13 & $<0.001$ & -0.14 & -0.17 to -0.10 & $<0.001$ \\
\hline Impact stigma score & 0.17 & $0.13-0.20$ & $<0.001$ & 0.17 & $0.13-0.201$ & $<0.001$ \\
\hline
\end{tabular}

ED emergency department, ICU intensive care unit, COVID-19 coronavirus disease-2019

Bold values: statistically significant at $P$ value $<0.05$ 
economic level during the initial coronavirus disease pandemic such as Pakistan, Latin American countries, and the USA [25-27].

Although nearly half exhibited no discrimination intent in treating COVID-19 patients, the majority (80\%) expected COVID-19 to be a severe disease with consequent morbidity and mortality; yet, they stated they will continue to work during the pandemic if they are fit and well. The main concern of our study respondents have is contracting COVID-19 infection and transmitting the infection to their loved ones.

At the time of administration of the survey, COVID19-confirmed patients were referred to assigned isolation hospitals. Establishing social constraints and restricting individuals' freedoms as working in quarantine or a confinement facility itself can generate fear and incite hysteria consequently and can exacerbate the stigma of the disease $[28,29]$. It is logical that these negative emotions and perceived feeling of stigma circulates among HCPS working in these conditions.

\subsection{Worry of contracting COVID-19}

In pandemics, psychological impacts such as fear and anxiety are natural, especially if the number of infected individuals and death rates is sharply increasing [30]. HCPs not only face overwhelming workload, PPE shortage, paucity of specific drugs, but they are also dealing with an uncertain threatening situation that may cause critical illness or death in addition to moral decisions regarding prioritization of whom to treat within limited resource settings. These circumstances are poised to cause mental discomfort and stir worry among them. In the current study, the majority of the studied HCPs were worried from contracting COVID 19 infections at work (94.7\%). In agreement to the current study, predominant proportions of Saudi, Ethiopian and Japanese HCPs felt worry about COVID-19 pandemic [21, 30, 31].

One of the factors that heighten the risk of infection among HCPs and increases their stress is that some patients conceal their contact history with confirmed or suspected COVID-19 patients because of the ongoing stigma related to the disease. The lack of PPEs as scrubs and disposable gowns represents a legitimate driver of worry about contracting the virus. This worry can be lowered if infection control measures are effectively employed. Research showed that the psychological effects of quarantine can still be detected months or years later and suggests the need to ensure that effective mitigation measures are put in place as part of the quarantine planning process [32].

Our study demonstrated that expecting COVID-19 to be a severe disease, believing that COVID-19 infection will not be successfully controlled, improbability to continue working during the pandemic even if fit, high discrimination intention towards COVID-19 patients, and perceiving stigma resulted from actions of surrounding subjects were risk factors for increased worry among HCPS to contract the infection while working in these circumstances. Our findings are consistent with recent research demonstrating that COVID-19 pandemic had psychological consequences in the form of negative emotions as fear, anxiety, and depression [33] especially among HCPs [34, 35]. Previous epidemics as severe acute respiratory syndrome (SARS) caused similar significant stress among frontline HCPs $[36,37]$. Our findings are consistent with other studies during SARS where emotions experienced by HCPs forced them to resign from their work or perform badly [38].

Our research highlighted that risk factors for severe worry among HCPs were high discrimination intention towards COVID-19 patients and perceiving stigma from actions of surrounding subjects while among risk factors of stigma were high perception of internalized shame from dealing with COVID-19 patients or work in its related field. The findings in our study confirm the mental health burden that Egyptian HCPs experienced at the COVID-19 pandemic. Effective psychological intervention programs for HCPs as assistance hotlines or smart use of social media applications for counselling should be designed [39].

\subsection{Stigma perception}

Studies from previous epidemics reported that HCPs who were quarantined suffered stigmatization and rejection in their local communities in comparison to those who were not quarantined [32, 38]. A study about the Liberia Ebola epidemic reported that stigma led some quarantined families to be excluded from the community and labelled as dangerous based on being of different ethnicity, tribes, or religion. This behavior led those who fell ill because of any disease to conceal their illness and evade seeking medical help [40]. High stigma perception from work-related COVID-19 exposure was reported among other Egyptian, Indonesian and Nigerian HCPs in the early phase of COVID-19 pandemic [41-43]. In accordance, a study investigated stigmatization against HCPs among non-health care workers. Reported stigmatization responses included the belief in placing severe restrictions on HCWs freedoms and HCPs should be kept in isolation from their communities and their families (more 25\% of respondents). Moreover, over a third of American and Canadian respondents avoided HCPs for fear of infection [44].

In the current study, adjusted regression showed that female health care workers were significantly at a higher risk for impact stigma than males. As regards infectious diseases, stigma was reported to be higher in women, and this could be attributed to women are 
traditionally expected to bear social rejection and negative self-image [45].

Media is a powerful tool in shaping public views and information and has previously contributed to stigmatization in prior outbreaks [32]. Researchers found that social media affected behaviors of risk perception [46]. Since the start of the pandemic, the Egyptian Ministry of Health $(\mathrm{MOH})$ started using sponsored ads on Facebook to educate the public about the disease as a way to use such a powerful tool in its favor [47]. However, with continuous fake news, rumors, and myths concerning COVID-19 easily circulating among the public, Egyptian HCPs became a target for discrimination.

\section{Study limitations}

This study has been conducted during the initial epidemic and quarantine duration in Egypt and before the construction and distribution of COVID-19 vaccines. Moreover, the data was collected using non-probability convenience sample mainly from HCPs in Upper Egypt. It is recommended to conduct national random representative study to evaluate the worry and stigma perception after vaccine availability.

\section{Conclusions}

Considerable levels of worry and stigma perceptions were detected among Egyptian HCPs during the COVID-19 outbreak. The health care system must engage HCPs in effective strategies to improve their mental health and offer psychological support and interventions. Other strategies include designing targeted education campaigns for destigmatizing COVID-19, addressing the public fear, and delivering updated health education initiatives about the disease within the official media outlets.

\section{Abbreviations \\ HCPS: Healthcare providers; $\mathrm{MOH}$ : Ministry of Health; SARS: Severe acute respiratory syndrome}

\section{Acknowledgements}

Not applicable

\section{Authors' contributions}

DM contributed to study design, analyzed the data in a minor extent, interpreted data, and prepared the main manuscript. FR contributed to study design and wrote the manuscript. GK contributed in study design and revised the manuscript. AY contributed to study design and wrote the manuscript. AM suggested the research idea, contributed to study design, and revised the manuscript. HM contributed to study design, collected the data, analyzed the data in a major extent, interpreted data, and shared in writing the manuscript. All authors red and approved the final manuscript.

\section{Funding}

This study did not receive any specific grant from the funding institution.

\section{Availability of data and materials}

The datasets generated and analyzed during the current study are available from the corresponding author on reasonable request.

\section{Declarations}

Ethics approval and consent to participate

The Nursing Ethical committee in Assiut University approved the study (IRB number 2490035). All ethical considerations were assured including obtaining an informed consent. As the questionnaire was collected using Google online method, it included an introductory statement about nature of the study, voluntary participation in the study, and the right to withdraw from the study at any time by using their registration code number without any negative consequences. The first question includes a requested participants' consent to be recruited in the study and their permission to use the data in scientific research and by submitting the online form, it indicated that the participant read the description of the study, understood the purpose and nature of this study, and agreed on the described terms. The researchers used anonymous questionnaire to preserve participants' privacy and confidentiality.

\section{Consent for publication}

Not applicable

\section{Competing interests}

The authors declare that they have no competing interests.

\section{Author details}

${ }^{1}$ Department of Public Health and Community Medicine, Faculty of Medicine, Assiut University, Assiut, Egypt. ${ }^{2}$ Family and Community Health Nursing, Faculty of Nursing, Assiut University, Assiut, Egypt. ${ }^{3}$ Department of Neurology and Psychiatry, Faculty of Medicine, Assiut University, Assiut, Egypt. ${ }^{4}$ Department of Child and Adolescent Psychiatry, Institute of Psychiatry, Psychology and Neuroscience, King's College London, London, UK. ${ }^{5}$ Department of Obstetrics and Gynecology, Faculty of Medicine, Assiut University, Assiut, Egypt.

Received: 24 September 2020 Accepted: 11 December 2021

Published online: 10 January 2022

\section{References}

1. Lipsitch M, Swerdlow DL, Finelli L. Defining the epidemiology of Covid-19: studies needed. N Engl J Med. 2020;382(13):1194-6. https://doi.org/10.1056/ NEJMp2002125.

2. WHO. WHO Coronavirus (COVID-19) Dashboard: World Health Organization; 2021 Available from: https://covid19.who.int/. Accessed 1 Dec 2021.

3. Cook TM. Personal protective equipment during the coronavirus disease (COVID) 2019 pandemic - a narrative review. Anaesthesia. 2020;75(7):920-7. https://doi.org/10.1111/anae.15071.

4. Sim MR. The COVID-19 pandemic: major risks to healthcare and other workers on the front line. Occup Environ Med. 2020;77(5):281-2. https://doi. org/10.1136/oemed-2020-106567.

5. Livingston $E$, Desai $A$, Berkwits M. Sourcing personal protective equipment during the COVID-19 pandemic. JAMA. 2020;323(19):1912-4. https://doi. org/10.1001/jama.2020.5317.

6. WHO. Mental health and COVID-19: World Health Organization - Regional Office for Europe; 2020. Available from: https://www.euro.who.int/en/healthtopics/noncommunicable-diseases/mental-health/data-and-resources/menta I-health-and-covid-19. Accessed 18 June 2020.

7. Kang L, Ma S, Chen M, Yang J, Wang Y, Li R, et al. Impact on mental health and perceptions of psychological care among medical and nursing staff in Wuhan during the 2019 novel coronavirus disease outbreak: a crosssectional study. Brain Behav Immun.. 2020:S0889-1591(20)30348-2. doi: 10. 1016/j.bbi.2020.03.028

8. WHO. Mental health and psychosocial considerations during the COVID-19 outbreak. World Health Organization; 2020 Available from: https://www. who.int/docs/default-source/coronaviruse/mental-health-considerations.pdf. Accessed 1 December 2021

9. ProMED. PRO/AH/EDR> COVID-19 update (03): China, global, Egypt, influenza surveillance, WHO. 2020. Available from: https://promedmail.org/ promed-posts/. Accessed 6 June 2020.

10. Zhong B-L, Luo W, Li H-M, Zhang Q-Q, Liu X-G, Li W-T, et al. Knowledge, attitudes, and practices towards COVID-19 among Chinese residents during the rapid rise period of the COVID-19 outbreak: a quick online crosssectional survey. Int J Biol Sci. 2020;16(10):1745-52. https://doi.org/10.7150/ ijbs.45221. 
11. Aldowyan N, Abdallah A, El-Gharbawy R. Knowledge, Attitude and practice (KAP) study about mddle east respiratory syndrome Coronavirus (MERS-CoV) among population in Saudi Arabia. Int Arch Med. 2017;10. https://doi.org/10.3823/2524.

12. REDcap. COVID-19 questionnaire Arabic version powered by REDcap 2020 Available from: https://www.redcap.ihrp.uic.edu/surveys/index.php?s=AT44 KR4HCE\&fbclid=IwAR30-fdCjO7_2vhYSpBGRhdPCsjh2KDh-bK9qHYTLwtdfVokQJt9X70GGQ. Accssed 29 Mar 2020

13. Engelbrecht M, Rau A, Kigozi G, Janse van Rensburg A, Wouters $E$, Sommerland $\mathrm{N}$, et al. Waiting to inhale: factors associated with healthcare workers' fears of occupationally-acquired tuberculosis (TB). BMC Infect Dis. 2019;19(1):475. https://doi.org/10.1186/s12879-019-4115-z.

14. Stein JA, Li L. Measuring HIV-related stigma among Chinese service providers: confirmatory factor analysis of a multidimensional scale. AIDS Behav. 2008;12(5):789-95. https://doi.org/10.1007/s10461-007-9339-z.

15. Li L, Lin C, Wu Z, Wu S, Rotheram-Borus MJ, Detels R, et al. Stigmatization and shame: consequences of caring for HIV/AIDS patients in China. AIDS care. 2007;19(2):258-63. https://doi.org/10.1080/09540120600828473.

16. Kapata N, Ihekweazu C, Ntoumi F, Raji T, Chanda-Kapata P, Mwaba P, et al. Is Africa prepared for tackling the COVID-19 (SARS-CoV-2) epidemic. Lessons from past outbreaks, ongoing pan-African public health efforts, and implications for the future. Int J Infect Dis. 2020;93:233-6. https://doi.org/1 0.1016/j.ijid.2020.02.049.

17. Bhagavathula AS, Aldhaleei WA, Rahmani J, Mahabadi MA, Bandari DK Knowledge and perceptions of COVID-19 among health care workers: crosssectional study. JMIR Public Health Surveill. 2020;6(2):19160. https://doi.org/1 $0.2196 / 19160$.

18. Tegegne GT, Kefale B, Engidaw MT, Degu A, Tesfa D, Ewunetei A, et al. Knowledge, attitude, and practice of healthcare providers toward novel Coronavirus 19 during the first months of the pandemic: a systematic review. Front Public Health. 2021;9:606666. https://doi.org/10.3389/fpubh.2021.606666.

19. Ahmad J, Anwar S, Latif A, Haq NU, Sharif M, Nauman AA. Association of PPE availability, training, and practices with COVID-19 sero-prevalence in nurses and paramedics in tertiary care hospitals of Peshawar, Pakistan. Disaster Med Public Health Prep. 2020:1-5. https://doi.org/10.1017/dmp.2020.438.

20. WHO. Rational use of personal protective equipment (PPE) for coronavirus disease (COVID-19) Geneva: World Health Organization; 2020. Available from: https://apps.who.int/iris/handle/10665/331498. Accessed 30 Nov 2021.

21. Deressa W, Worku A, Abebe W, Gizaw M, Amogne W. Risk perceptions and preventive practices of COVID-19 among healthcare professionals in public hospitals in Addis Ababa, Ethiopia: Randomized Controlled Trial. PLOS ONE. 2021;16(6):e0242471. https://doi.org/10.1371/journal.pone.0242471.

22. Albahri AH, Alnaqbi SA, Alnaqbi SA, Alshaali AO, Shahdoor SM. Knowledge, attitude, and practice regarding COVID-19 among healthcare workers in primary healthcare centers in Dubai: a cross-sectional survey, 2020. Front Public Health. 2021;9(1080). https://doi.org/10.3389/fpubh.2021.617679.

23. WHO. Keep health workers safe to keep patients safe: WHO Geneva: World Health Organization; 2020 .Available from: https://www.who.int/news/item/1 7-09-2020-keep-health-workers-safe-to-keep-patients-safe-who. Accssed 28 November 2021

24. OSHA. COVID-19 - Control and Prevention: Healthcare Workers and Employers Washington, DC: Occupational Safety and Health Administration 2021. Available from: https://www.osha.gov/coronavirus/control-prevention/ healthcare-workers. Accessed 27 November 2021.

25. Ahmed J, Malik F, Bin Arif T, Majid Z, Chaudhary MA, Ahmad J, et al. Availability of personal protective equipment (PPE) among US and Pakistani doctors in COVID19 pandemic. Cureus. 2020;12(6):e8550-e. https://doi.org/10.7759/cureus.8550.

26. Martin-Delgado J, Viteri E, Mula A, Serpa P, Pacheco G, Prada D, et al. Availability of personal protective equipment and diagnostic and treatment facilities for healthcare workers involved in COVID-19 care: a cross-sectional study in Brazil, Colombia, and Ecuador. PLOS ONE. 2020;15(11):e0242185. https://doi.org/10.1371/journal.pone.0242185.

27. Deressa W, Worku A, Abebe W, Gizaw M, Amogne W. Availability and use of personal protective equipment and satisfaction of healthcare professionals during COVID-19 pandemic in Addis Ababa. Ethiopia. Arch Public Health. 2021;79(1):146. https://doi.org/10.1186/s13690-021-00668-3.

28. Barbisch D, Koenig KL, Shih F-Y. Is there a case for quarantine? perspectives from SARS to Ebola. Disaster Med Public Health Prep. 2015;9(5):547-53. https://doi.org/10.1017/dmp.2015.38.

29. Badrfam R, Zandifar A. Stigma over COVID-19: new conception beyond individual sense. Arch Med Res.2020:S0188-4409(20)30754-2. https://doi. org/10.1016/j.arcmed.2020.05.006.
30. Mohsin SF, Agwan MA, Shaikh S, Alsuwaydani ZA, AlSuwaydani SA. COVID19: fear and anxiety among healthcare workers in Saudi Arabia. a crosssectional study. Inquiry. 2021;58:00469580211025225. https://doi.org/10.11 77/00469580211025225.

31. Sahashi $Y$, Endo H, Sugimoto T, Nabeta T, Nishizaki K, Kikuchi A, et al. Worries and concerns among healthcare workers during the coronavirus 2019 pandemic: a web-based cross-sectional survey. Humanit Soc Sci Commun. 2021;8(1):41. https://doi.org/10.1101/2020.06.09.20126045.

32. Brooks SK, Webster RK, Smith LE, Woodland L, Wessely S, Greenberg N, et al. The psychological impact of quarantine and how to reduce it: rapid review of the evidence. The lancet. 2020;395(10227):912-20. https://doi.org/10.101 6/S0140-6736(20)30460-8.

33. Li S, Wang Y, Xue J, Zhao N, Zhu T. The impact of COVID-19 epidemic declaration on psychological consequences: a study on active Weibo users. Int J Environ Res Public Health. 2020;17(6). https://doi.org/10.3390/ijerph1 7062032.

34. Lu W, Wang H, Lin Y, Li L. Psychological status of medical workforce during the COVID-19 pandemic: a cross-sectional study. Psychiatry Res. 2020;288: 112936. https://doi.org/10.1016/j.psychres.2020.112936.

35. Lai J, Ma S, Wang Y, Cai Z, Hu J, Wei N, et al. Factors associated with mental health outcomes among health care workers exposed to Coronavirus disease 2019. JAMA Network Open. 2020;3(3):e203976-e. doi: 10.1001/ jamanetworkopen.2020.3976

36. Tam CW, Pang EP, Lam LC, Chiu HF. Severe acute respiratory syndrome (SARS) in Hong Kong in 2003: stress and psychological impact among frontline healthcare workers. Psychol Med. 2004;34(7):1197-204. doi: 10.1017/ s0033291704002247

37. Lu YC, Shu BC, Chang YY, Lung FW. The mental health of hospital workers dealing with severe acute respiratory syndrome. Psychother Psychosom. 2006;75(6):370-5. https://doi.org/10.1159/000095443.

38. Bai Y, Lin CC, Lin CY, Chen JY, Chue CM, Chou P. Survey of stress reactions among health care workers involved with the SARS outbreak. Psychiatr Serv. 2004;55(9):1055-7. https://doi.org/10.1176/appi.ps.55.9.1055.

39. Lima CKT, Carvalho PMdM, Lima IdAAS, Nunes JVAdO, Saraiva JS, de Souza $\mathrm{Rl}$, et al. The emotional impact of Coronavirus 2019-nCoV (new Coronavirus disease). Psychiatry Research. 2020;287:112915. https://doi.org/10.1016/j. psychres.2020.112915.

40. Pellecchia U, Crestani R, Decroo T, Van den Bergh R, Al-Kourdi Y. Social consequences of ebola containment measures in Liberia. PLOS ONE. 2015; 10(12):e0143036. https://doi.org/10.1371/journal.pone.0143036.

41. Mostafa A, Sabry W, Mostafa NS. COVID-19-related stigmatization among a sample of Egyptian healthcare workers. PLOS ONE. 2020;15(12):e0244172. https://doi.org/10.1371/journal.pone.0244172.

42. Kwaghe AV, Ilesanmi OS, Amede PO, Okediran JO, Utulu R, Balogun MS. Stigmatization, psychological and emotional trauma among frontline health care workers treated for COVID-19 in Lagos State, Nigeria: a qualitative study. BMC Health Serv Res. 2021;21(1):855. https://doi.org/10.1186/s12913021-06835-0.

43. Yufika A, Pratama R, Anwar S, Winardi W, Librianty N, Prashanti NAP, et al. Stigma associated with COVID-19 among health care workers in Indonesia. Disaster Med Public Health Prep. 2021:1-5. https://doi.org/10.1017/dmp.2 021.93.

44. Taylor S, Landry CA, Rachor GS, Paluszek MM, Asmundson GJG. Fear and avoidance of healthcare workers: an important, under-recognized form of stigmatization during the COVID-19 pandemic. J Anxiety Disord. 2020;75: 102289. https://doi.org/10.1016/j.janxdis.2020.102289

45. Ataro Z, Mengesha MM, Abrham A, Digaffe T. Gender differences in perceived stigma and coping strategies among people living with HIV/AIDS at Jugal Hospital, Harar. Ethiopia. Psychol Res Behav Manag. 2020;13:1191200. https://doi.org/10.2147/PRBM.S283969.

46. Bruns DP, Kraguljac NV, Bruns TR. COVID-19: facts, cultural considerations, and risk of stigmatization. J Transcult Nurs. 2020;31(4):326-32. https://doi. org/10.1177/1043659620917724.

47. Abdelhafiz AS, Mohammed Z, Ibrahim ME, Ziady HH, Alorabi M, Ayyad M, Sultan EA Knowledge, perceptions, and attitude of Egyptians towards the novel Coronavirus Disease (COVID-19). J Community Health.2020:1-10. doi: https://doi.org/10.1007/s10900-020-00827-7, 45, 5

\section{Publisher's Note}

Springer Nature remains neutral with regard to jurisdictional claims in published maps and institutional affiliations. 